\title{
A PARASITIC COPEPOD BELONGING TO THE GENUS MEDESICASTE (KRØYER), AND ITS RELATION TO THE TUMOURS IT PRODUCES ON THE FISH, TRIGLA GURNARDUS.
}

\author{
By W. HAROLD LEIGH-SHARPE, M.Sc. (LoND.).
}

(With 7 Text-figures.)

Habitat and record. The genus Medesicaste (Krøyer), belonging to the family Chondracanthidae, is usually considered to be represented by but one British species, Medesicaste asellinum (Linn.) ${ }^{\mathbf{1}}$, whose characters are diagnosed as very variable. It is open to question whether the additional appendicular details given herein and the presence of the conjunctive tubes (vide infra) are sufficient to warrant the erection of a new species.

The following observations were made upon eight specimens of Medesicaste $q$ taken from various Trigla gurnardus caught at Lowestoft in August, 1918. They were, without exception, upon the gills, upon which they cause characteristic tumours.

Body. The outline of the animal is best seen from Figs. 1 and 2. The cephalothorax consists of a subglobose anterior end or head, bearing the antennules and antennae, and a considerably elongated slender neck at the base of which are situated the mouth and the other cephalic and thoracic appendages, which are thus widely separated from the antennae.

The head is $1.4 \mathrm{~mm}$. long, bulbous, trilobate, rounded in front, with each side expanded into a hemispherical lobe. The neck, which has its posterior portion enlarged, is $1.8 \mathrm{~mm}$. long. Both head and neck as far as the mouth are embedded in the tumour which is formed upon the gill-filaments of the host.

The trunk is square in outline, $2.4 \mathrm{~mm}$. long, slightly wider than long. It is divided by a deep transverse constriction into two almost equal parts; the anterior constituting the thorax bearing appendages, carrying two pairs of obtuse processes ventrally and a small pair dorsally; the posterior, the larger, the genital segment, the antero-lateral corners of which extend outwards into angular projections. The lateral margins of this posterior division are arcuate, converging distally, and forming two small postero-lateral lobes between which is a small medio-ventral $\mathbf{V}$-shaped depression or sinus.

1 A full list of references and synonyms is given by Scott and Scott (1913). The British Parasitic Copepoda, The Ray Society, London. The only fairly good figure is that in this work, Plate LII, fig. 6. 
The two ventral anterior thoracic processes curve ventrally and frequently meet. Each process bears a pair of pronounced, fleshy appendages, also curved, and always meeting, so that most specimens appear to have a fleshy loop at this point caused by the interlocking of the apical "digits."

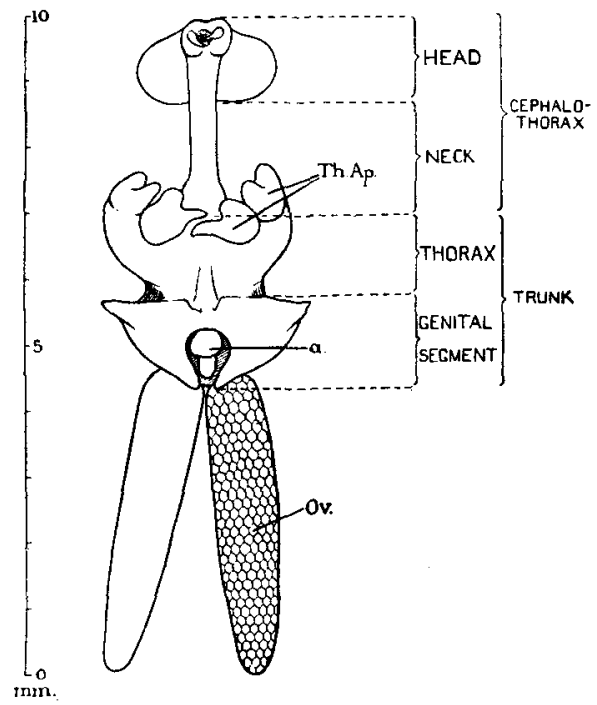

Fig. 1. Medesicaste. Ventral aspect. a. abdomen; Ov. ovisacs; Th.Ap. two pairs of ventral thoracic appendages.

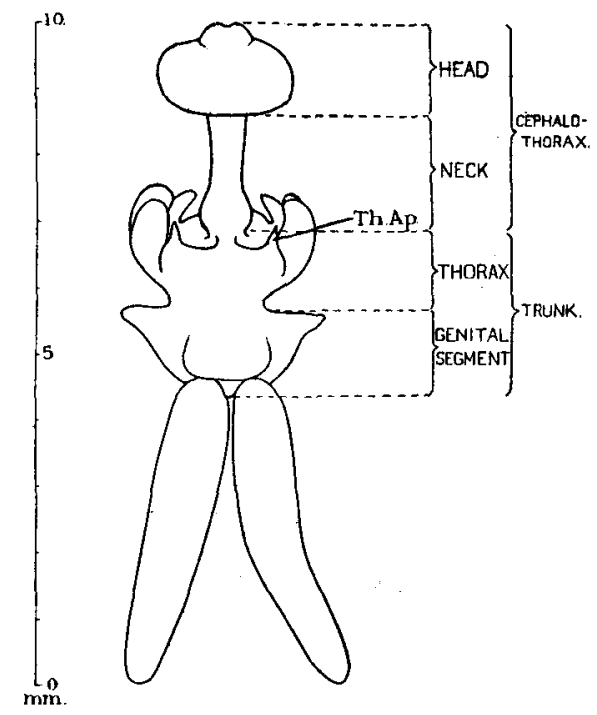

Fig. 2. Medesicaste. Dorsal aspect. Th.Ap. one pair of dorsal thoracic appendages.

The abdomen is very small, bi-articulated, the posterior segment being the larger, and enclosed between the postero-lateral lobes. There are no abdominal appendages. 
The ovisacs are $4.4 \mathrm{~mm}$. long, longer than the trunk, of a dark brown colour, and show externally six rows of ova, 31 in a row.

The total length of the preserved animal is about $10 \mathrm{~mm}$. A fully developed female is found embedded in a relatively small tumour, has a larger trunk, bears two ovisacs, and has no trace of conjunctive tubes.

The appendages, all paired, none of them setigerous, are, in order, as follows (Fig. 3): The antennules are minute, two-jointed, the joints not making

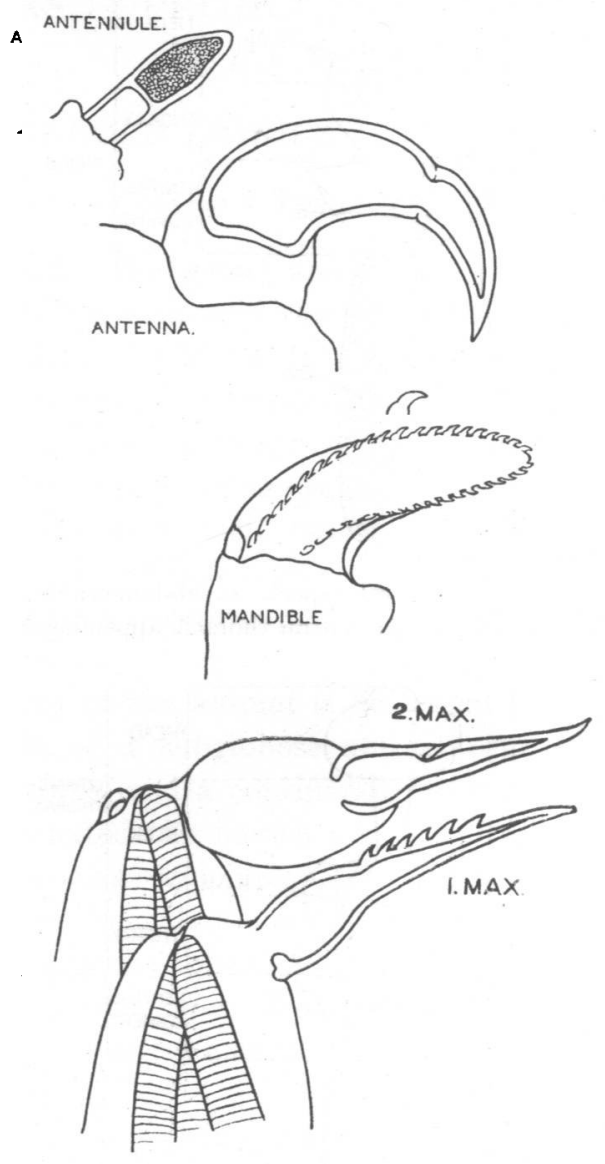

Fig. 3. Medesicaste. The appendages.

any angle with one another. The terminal joint is rounded. They are situated dorsally and are barely half the size of the antennae. The antennae (Figs. 3 and 4) are ventral, two-jointed, short and stout. The terminal joint, which is much the longer, terminates in a powerful, incurved, sharp-pointed claw. The mandibles are falciform as is usual in this family, instead of styliform as in the Lernaeopodidae, broad at the proximal end, and tapering to a more or less attenuated distal extremity. Both margins appear minutely serrated under a low magnification, but in reality the teeth, which resemble prickles, 
are set at right angles to the undersurface of the lamina, and are marginal only at the apex, while they form a loop and do not approach the margin at the base. Towards the convex edge of the lamina the number of teeth is twenty; along the concave edge they are more numerous.

There follow two pairs of appendages of uncertain homology, variously styled maxillae or maxillipedes. They are both on the same plan, two-jointed, there being in each case a stout basal joint, with a bulbous distal joint, terminating in a long straight style. The anterior pair is distinguishable by having

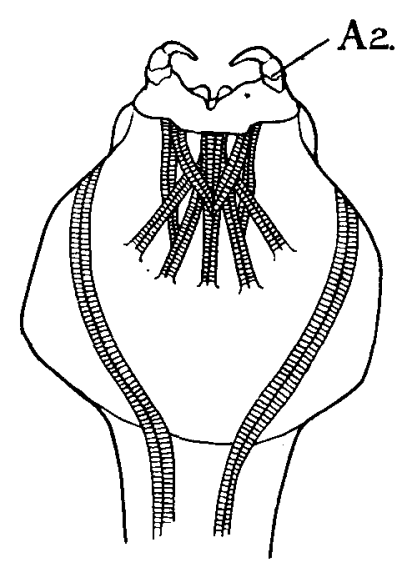

Fig. 4. Medesicaste. The anterior end, with the antennae $(A 2)$ in the erect position.
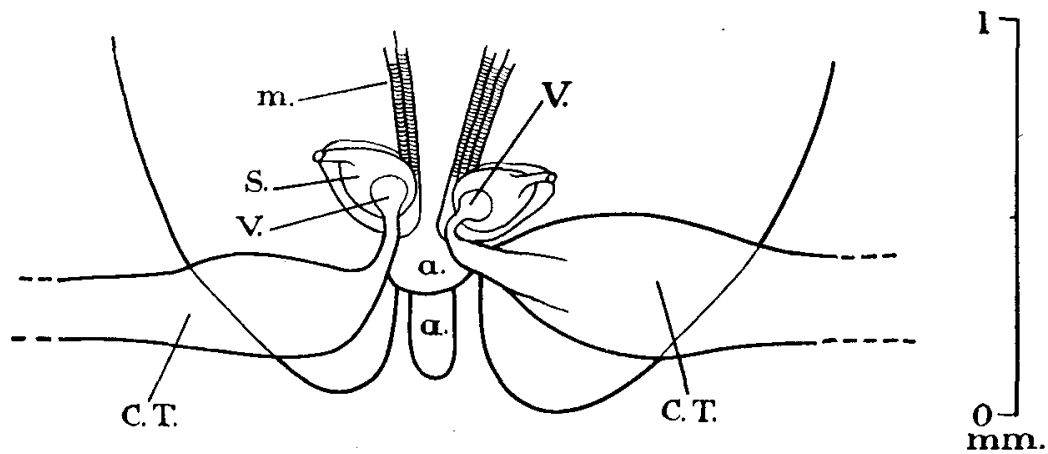

Fig. 5. Medesicaste. The posterior end. a. abdomen; $m$. muscle; $V$. vulvae; $S$. spermathecae; $C . T$. conjunctive tubes.

the inner margin of the style strongly serrated (Fig. 3, 1 max.). There are six large, stout spines away from the apex which interlock in a scissor-like manner with those of its partner. The thoracic appendages have already been described (v. supra); their surface is covered with numerous very minute prickles.

The most striking feature, now for the first time described, is the presence of the conjunctive tubes. These occur in three of the specimens, which are immature, bear no ovisacs and are embedded in relatively large tumours. 
These tubes are paired, for although only one is preserved entire in each of the specimens, the broken end of the second is present in the best specimen (Fig. 6). The tubes are attached to the vulvae of the female and communicate directly with the spermathecae, the ovisacs issuing forth dorsally at another aperture. The reproductive system is on the same general plan as I have described for Lernaeopoda (Parasitology, vIII. 269 and Fig. 6), the ovaries occupying the arcuate lateral portions of the genital segment.

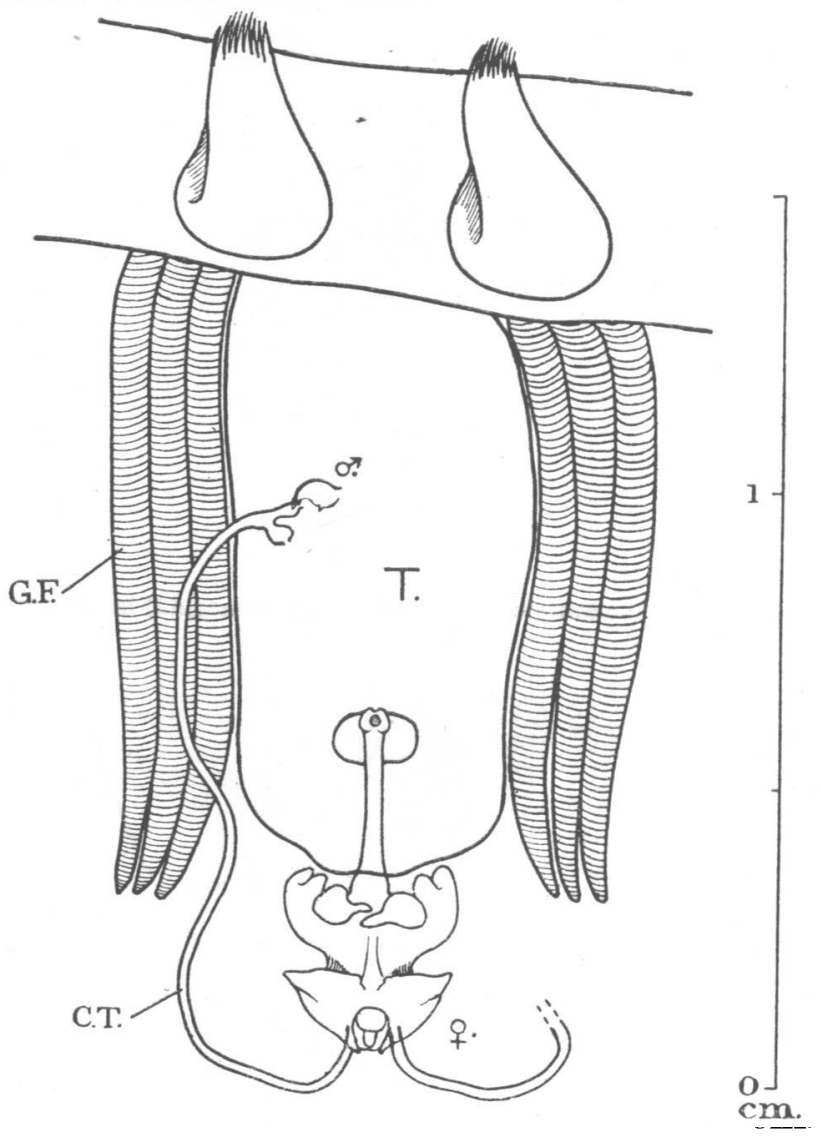

Fig. 6. Medesicaste. A diagrammatic representation of the relative positions of the two sexes with regard to the tumour on the host. T. tumour; G.F. gill filaments of host; $\&$ female animal; ơ male animal; C.T. conjunctive tubes.

A most remarkable phenomenon is that the other end of the tube, which is long, free, flexible and sinuous, enters the upper portion of the same tumour as that in which the head and neck of the female are embedded, where it bifurcates; hence the term "conjunctive" (Fig. 6). The tube is one third the width of a gill filament, and about $12 \mathrm{~mm}$. long.

The tumour produced by the parasite is structureless and is to be regarded as a hypertrophied gill filament. It may be irregular, but is usually clavate, 
with or without a constricted neck, about seven times the breadth of a normal gill filament. No doubt the hypertrophy was occasioned by the penetration of the free-swimming nauplius larva into the tissues of the gill filament.

At the proximal bifurcation of the conjunctive tube, deep within the tumour, are the faint traces of what appear to be the remains of the cuticle of a dead and disintegrated male, the only certain detail of which is the rounded dorsum (Fig. 7). If this be proved, the tubes might be definitely called conjugation tubes, exhibiting an occurrence wholly unique. During the past four years I have examined some hundreds of gurnards without finding Medesicaste, neither has that genus been taken at the laboratory of the Marine Biological Association, Plymouth, though specially sought at my request.

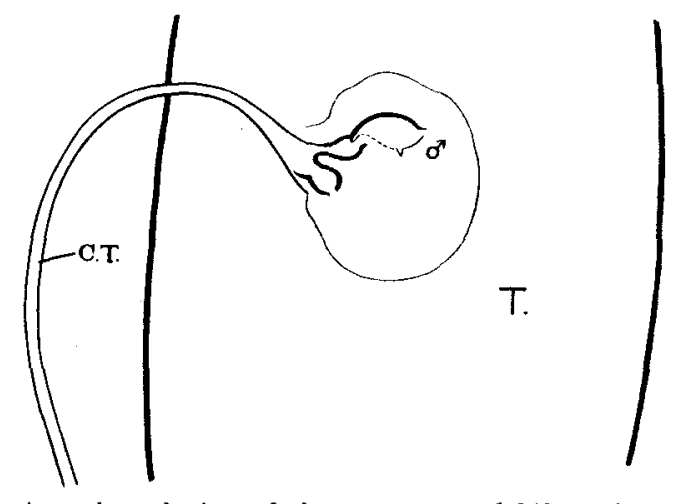

Fig. 7. Medesicaste. An enlarged view of the entrance and bifurcation of a conjunctive tube $(C . T$.$) in the tumour \left(T^{\top}\right)$. of remains of male animal.

\section{- SUMMARY.}

A tumour among the gill filaments of Trigla gurnardus bears a female Medesicaste with the head and neck buried in its apex, and a male Medesicaste completely embedded in its base. The two sexes of the parasite are connected by a conjugation tube, external to the tumour, down which tube the spermatophores presumably pass. The appendages of the copepod are described.

My thanks are due to Michael G. L. Perkins for furnishing me with the specimens, and to Miss Edith C. Humphreys for drawings of the specimens and preparations which are all mounted unstained in Farrant's medium. 